\title{
Conceptual model for intensive care nurse work wellbeing: A qualitative secondary analysis
}

Manuscript type: Original research paper

Keywords: conceptual model; ICU nurses; knowledge translation; qualitative secondary analysis; wellbeing.

\section{Authors:}

1) Rebecca J Jarden (first \& corresponding author): Ph.D., R.N.; Department of Nursing, Melbourne School of Health Sciences, 161 Barry St, Carlton, Victoria 3053, Australia; phone: 0061 383440734; rebecca.jarden@unimelb.edu.au.

2) Margaret Sandham: (research team member); BHSc (Nursing), DClinPsych., School of Clinical Sciences, Auckland University of Technology (AUT), North Shore Campus, 90 Akoranga Drive, Northcote, Auckland 0627, New Zealand; margaret.sandham@aut.ac.nz.

3) Richard J Siegert: (research team member); Ph.D.; School of Clinical Sciences and School of Public Health and Psychosocial Studies, Auckland University of Technology (AUT), North Shore Campus, 90 Akoranga Drive, Northcote, Auckland 0627, New Zealand; richard.siegert@aut.ac.nz.

4) Jane Koziol-McLain: (research team member); Ph.D., R.N.; School of Clinical Sciences, Auckland University of Technology (AUT), North Shore Campus, 90 Akoranga Drive, Northcote, Auckland 0627, New Zealand; jane.koziol-mclain@aut.ac.nz.

Acknowledgements: Thank you to the New Zealand ICU RNs who participated in the study.

Conflict of interest statement: The authors have no conflicts of interest to declare

Funding and financial disclosure: This research has not received funding.

This is the author manuscript accepted for publication and has undergone full peer review but has not been through the copyediting, typesetting, pagination and proofreading process, which may lead to differences between this version and the Version of Record. Please cite this article as doi: 10.1111/nicc.12485

This article is protected by copyright. All rights reserved. 
Aims and objectives: Synthesise intensive care nurse perceptions of work wellbeing characteristics and strengtheners to identify opportunities for job crafting and redesign.

Background: There had been little focus on the wellbeing of intensive care nurses until a recent programme of research found work wellbeing to be best described as a collection of elements; a multifaceted construct. Strengtheners of intensive care nurses' work wellbeing were found to extend across individual, relational, and organisational resources. Actions such as simplifying their lives, giving and receiving team support, and accessing employee assistance programmes were just a few of the intensive care nurses' identified strengtheners.

Design: A qualitative secondary analysis.

Methods: Intensive care nurse work wellbeing characteristics and strengtheners were explored using applied thematic analysis and pre-design, open card-sort technique.

Findings: Five facets were identified in the analysis: 1) healthy, 2) authentic, 3) meaningful, 4) connected, and 5) innovative. These five facets were described from a theoretical perspective and illustrated as a conceptual model for intensive care nurse job crafting and redesign. Conclusions: The proposed conceptual model contributes new knowledge to now be explored in meaningful discussions about intensive care nurse work wellbeing, and empirically investigated in terms of construct validity and theory development. Further, the model provides 
practical opportunities to explore individual and collaborative ways to enhance intensive care nurse work wellbeing across a range of levels.

Relevance to clinical practice: Opportunities for job crafting and redesign were identified and presented in a conceptual model of intensive care nurse work wellbeing. This model provides individual nurses, intensive care teams, healthcare organisations, and workers' wellbeing programme and policy developers practical opportunities to explore individual and collaborative ways to enhance intensive care nurse work wellbeing.

This article is protected by copyright. All rights reserved. 


\section{INTRODUCTION}

Intensive care nurses are exposed to various psychological risks with the potential of psychological harm, such as burnout ${ }^{1,2}$, compassion fatigue ${ }^{3}$, moral distress ${ }^{4}$, and bullying ${ }^{5}$. These harms have been the focus of a large body of international research exploring illbeing or the 'negative side' of wellbeing; ${ }^{6}$. More recently, global leaders have called for a shift in our gaze from nurse illbeing (as opposed to illness which has a strong focus on physical health) to nurse health and wellbeing ${ }^{7}$. The emerging field of positive psychology suggests the value in balancing the focus on illbeing with a focus on wellbeing, moving towards approaches related to strengths ${ }^{8}$, thriving ${ }^{9}$, flourishing ${ }^{10,11}$, resilience ${ }^{12}$, and optimal functioning ${ }^{13}$.

\section{BACKGROUND}

\section{Wellbeing}

The varied theoretical underpinnings of wellbeing have grown from a wide range of perspectives, for example, Maslow's Hierarchy of Needs ${ }^{14}$, Flow Theory ${ }^{15}$, Self-Efficacy Theory (an example of a Social Learning Theory) ${ }^{16,17}$, Bronfenbrenner's Ecological Systems Theory ${ }^{18,19}$, Control Theory ${ }^{20}$, Bowlby's Attachment Theory ${ }^{21,22}$, and Self-Determination Theory ${ }^{23}$. Along with these various theories, there are a broad range of definitions of wellbeing ${ }^{24}$. For example, "the balance point between an individual's resource pool and the challenges faced" 25, p. 230, "the combination of feeling good and functioning effectively" 26, p. 139 , and "subjective bodily and emotional states; how an individual feels; a state of mind distinct from functioning that pertains to behaviours and activities" 27, para. 4 . 
Models of wellbeing include that of the World Health Organisation WHO; ${ }^{28}$, with six proposed categories of concepts for positive psychological health; Ryff ${ }^{29}$, with six dimensions of psychological wellbeing (or mental wellbeing; as opposed to wellbeing in more global terms); Ryan and Deci ${ }^{30}$ who describe wellbeing as a complex construct related to both optimal experience and optimal functioning; Seligman who suggested wellbeing equates to human flourishing, based on five elements; and Huppert and So ${ }^{31}$, for whom flourishing is a combination of feeling good and functioning effectively.

\section{Work wellbeing}

More than 60 percent of New Zealanders are employed ${ }^{32}$, reflecting similar global rates ${ }^{33}$. The key aspects of working conditions proposed to affect employees can broadly be categorised into job design and physical workplace design ${ }^{34}$. Job design is a potential enabler of wellbeing whether related to work demands (physical, cognitive and emotional), job role (clarity and alignment), work hours (shift work, flexibility and overtime), job control (flexibility in meeting the demands of the job), or social support (emotional and informational). The relationship of the job's characteristics with employee motivation, engagement, satisfaction, and performance has previously been described both in theory and various models, for example the Job Characteristics Theory ${ }^{35}$, Person-Organisation Fit Theory ${ }^{36}$, and the Job Demands-Resources Model ${ }^{37}$. Workplace design not only relates to optimal operation, but safety and comfort. Job crafting and redesign are an approach to enhancing workplaces by changing the task or relational boundaries of work to improve working conditions ${ }^{38,39}$ with a focus on modifying environmental (as opposed to personal) sources of wellbeing in a pragmatic approach to improve wellbeing ${ }^{40}$. 


\section{RESEARCH OBJECTIVE}

In a research programme of mixed methods, two studies sought to conceptualise intensive care nurse work wellbeing and it's strengtheners. Firstly, a prototype analysis identified ICU nurses' conceptions of work wellbeing (Blinded for peer review). Secondly, an exploratory descriptive study identified strengtheners of ICU nurse work wellbeing (Blinded for peer review). The objective of this qualitative secondary analysis was to re-explore these ICU nurse work wellbeing conceptions and strengtheners from a job crafting and redesign perspective ${ }^{38,}{ }^{39}$, drawing from their synergistic effect to develop a conceptual model and inform future work wellbeing initiatives, programmes and interventions.

\section{DESIGN AND METHODS}

\section{Ethical considerations}

This study was a qualitative secondary analysis using data from two parent studies (Blinded for peer review; Blinded for peer review). These parent studies were conducted in accordance with the Auckland University of Technology Ethics Committee approval (17/180), reported previously (Blinded for peer review; Blinded for peer review). The secondary analysis of qualitative data is recommended as a method of contributing to ethical research by doing justice to participants' contributions ${ }^{41}$, and as an effective means of analysis to inform policy decision making ${ }^{42}$.

Sample and setting

This article is protected by copyright. All rights reserved. 
The sample for the parent studies were New Zealand ICU nurses. For the prototype analysis, 82 nurses were randomised into three sub-studies (sub-study $1, n=30$; sub-study $2, n=30$; sub-study $3, n$ $=22$ ) which identified, rated, then tested the characteristics of their work wellbeing. For the strengtheners of work wellbeing, 65 of these nurses responded to online free-text questions. This reflected a largely representative sample of the New Zealand ICU nurse population.

\section{Data analysis}

For this secondary analysis, the ICU nurse work wellbeing characteristics and their strengtheners from the parent studies were re-explored using an applied thematic analysis ${ }^{43-45}$ and predesign, open card-sort technique ${ }^{46,47}$. One researcher (Blinded for peer review) categorised and coded the characteristics and strengtheners independently, then three researchers (Blinded for peer review) reviewed and resolved any uncertainty in relation to the categorising into themes, labelled as 'facets'. The term 'facets' was not selected lightly, with its definition stemming from many faces or sides, and being a part of something bigger such as a gem ${ }^{48}$. The framework of 'me', 'we', and 'us' ${ }^{49}$ was employed as a conceptual scheme.

\section{FINDINGS}

Moving beyond explicit meanings within the data, the broader patterns and significant implications for enhancing ICU nurse work wellbeing highlight five facets of ICU nurse work wellbeing as being: healthy, authentic, meaningful, connected and innovative. The facets were named using 
adjectives to support them becoming ICU mission statements, such as, 'our ICU is healthy, authentic, meaningful, connected and innovative'. These facets scaffold the integration of the empirical and ICU nurse perspectives from the findings of this programme of research. The ICU nurse work wellbeing characteristics (blinded for peer review) and their strengtheners (blinded for peer review) were reanalysed and sorted according to the five facets, then reported alphabetically (see Table 1).

Insert Table 1 here

Within each of the five facets, all three levels of strengtheners (i.e., ' $m e^{\prime}$, 'we' \& 'us' ${ }^{49}$ were evident, reflecting the opportunity for innovation from individual's building and drawing on personal resources, strengths and power, through to those of the teams and organisations. These five facets are positioned in terms of the theoretical foundations of wellbeing such as Maslow's Hierarchy of Needs ${ }^{14}$, Person-Environment Fit Theory ${ }^{50}$, Self-Determination Theory ${ }^{23}$ and Flow Theory ${ }^{51}$. For example, for Self-Determination Theory ${ }^{23}$, employees with satisfied basic needs demonstrate autonomous motivation, and for Flow Theory ${ }^{51}$, being in a state of flow results in individuals being happier when engaged in an activity and seeking it out. These five facets are now discussed in further detail.

Healthy

Facet one, healthy broadly encompasses being physically and psychologically energised and experiencing balance. This facet's theoretical underpinnings include meeting the basic needs highlighted in Maslow's Theory of Motivation: physiological safety, love, esteem, and self-actualisation ${ }^{14}$. When an individual's needs and values are satisfied, predictors of life satisfaction move from safety 
needs, to satisfaction with love and esteem, with some cross-cultural variation in values ${ }^{52}$. In addition, Self-Determination Theory suggests supporting employees to satisfy these basic physiological needs facilitates autonomous motivation ${ }^{53}$.

The ICU nurses' proposed work wellbeing characteristics for the facet of healthy ranged from physical and mental health, to rostering and resilience. The nurses' identified strengtheners included access to nutrition and hydration; an environment well suited for working requirements; appropriate attire; financial security; emotional, psychological, physical safety; accessible support systems and personal relationships such as friendships, partners and family. Integrating the ICU nurses' conceptions of work wellbeing characteristics and strengtheners with this theme suggests for ICU nurses, healthy, could include workplaces enhancing support for active healthy lifestyles, accessible nutritious and healthy food options, easily adjustable furniture to fit sizes, needs, and preferences and incorporation of nature; whether this is bringing nature in or heading outside. The characteristics and strengtheners underpinning the healthy facet are presented in Table 1.

The work wellbeing job crafting and design innovations related to this facet include access to nutrition and hydration; an environment well suited for working requirements; appropriate attire; financial security; emotional, psychological, physical safety; accessible support systems; personal relationships such as friendships, partners and family; workplace relationships such as friendship and mentoring; feeling part of a group; engagement in activities that aligned with their strengths and contribute to a feeling of fulfilment.

\section{Authentic}


Facet two, authentic broadly encompasses being in the moment, genuine, real, and true to oneself. The ICU nurses' proposed work wellbeing characteristics for the facet of authentic ranged from experiencing energy and humour to workplace culture. Examples of the nurses' identified strengtheners included mindfulness and meditation, communication and experiencing respect.

The authentic facet's theoretical underpinnings include Authentic Leadership Theory ${ }^{54}$, Flow Theory ${ }^{15}$, Self-Determination Theory ${ }^{53}$, and Person-Environment Fit Theory ${ }^{50}$. Avolio and Gardner ${ }^{54}$ propose authentic leadership influences organisations by supporting people to find meaning in work, building optimism and commitment and transparent trusting relationships. From this state of meaningful work, an individual may become so involved in an activity that they experience a state of flow in which nothing else is noticed. This state of flow results in individuals being happier when engaged in this activity and seeking it out ${ }^{51}$. Flow was created with clear goals, intense concentration, a sense of control, perceived balance of skills and challenge, and clear feedback. Flow experiences at work, such as in situations of skill variety and autonomy, positively influence employee wellbeing ${ }^{55,56 .}$ The sense of variety and autonomy may support individuals to feel more comfortable and authentic whilst working, with associated enhanced wellbeing and work outcomes ${ }^{57}$. This authenticity can occur at an individual-level, where there are positive correlations between authenticity and wellbeing ${ }^{58}$, and also at a team-level where an authentic climate mitigates emotional exhaustion ${ }^{59}$. Self-Determination Theory ${ }^{23,53}$ suggests both autonomy and competence cultivate authenticity. Heppner, Kernis ${ }^{60}$ identified positive correlations between satisfaction of autonomy, competence and relatedness needs and authenticity. Given that acting authentically may at times go against what others see as the best 
way forward, according to Peterson and Seligman ${ }^{61}$, authenticity also sits within the character strength of courage.

Integrating the ICU nurses' conceptions of work wellbeing characteristics and strengtheners with this theme suggests that for ICU nurses, authentic, could mean 1) workplaces including design features for rest or re-energising in break-out rooms that have both high and low stimulus options for aspects such as lighting, technology and music, 2) opportunities for keeping active at work, and 3) workforce and staffing designed for safe and effective work which might include clear goal setting, freely accessible professional development, support for role variation and opportunities to seek immediate feedback. Leaders and managers might consider authentic strengths-based strategies to support nurses' competence, autonomy, choice and variety. The characteristics and strengtheners underpinning the authentic facet are presented in Table 1.

The work wellbeing job crafting and design innovations related to this facet include, for leaders and at a team-level, 1) adopting authentic leadership strategies such as supporting workers choice, variety, autonomy and job challenge, 2) supporting basic needs to be met, 3) giving clear feedback, and 4) listening to and being open to new opportunities proposed by employees who are being authentic to their true self. At an individual level being authentic may include 1) self-advocating for your basic needs, 2) challenging oneself by setting goals, 3) seeking variety, and 4) identifying and having courage to stand by your values to support the development of meaning and authenticity in work.

\section{Meaningful}


Facet three, meaningful broadly encompasses meaning, purpose and values. The meaningful facet is underpinned by Social Information Processing Theory, which suggests coworkers influence job attitudes through cues they give about thoughts and feelings ${ }^{62}$. Meaning in life is thought to involve one making sense of and integrating experiences to create understanding of ourselves and how we understand and fit within the world around us, and then purpose, or the motivation to actively pursue goals that reflect one's identity ${ }^{63}$. Meaningfulness and happiness are positively correlated ${ }^{64}$ and are both considered core components of a good life and overlap in a number of ways, although at times there are trade-offs between the two ${ }^{65}$. Meaningfulness is thought to be both a cognitive and an emotional assessment of the purpose and value in one's life ${ }^{64}$. Many factors contribute similarly to both, such as feeling connected to others and feeling productive, although meaningfulness independently relates to expressing oneself and considering the past, present and future ${ }^{64}$.

The ICU nurses' proposed work wellbeing characteristics for the facet of meaningful ranged from feeling appreciated, being able to care, and having confidence in practice. Examples of the nurses' identified strengtheners included showing appreciation, experiencing teamwork, debriefing, and supportive and encouraging management. Integrating the ICU nurses' conceptions of work wellbeing characteristics and strengtheners with this theme suggests for ICU nurses, meaningful, could mean identifying organisational activities to proactively engage, build and share common organisational and specialty purpose, and collaborative approaches to identifying purpose drawing from online forums and team-based activities. Supporting professional development activities through shared identification of professional development needs drawing from strength-based approaches, then support to attend a range of professional development activities using various modalities. Learning and adopting positive 
organisational scholarship approaches ${ }^{66}$ to enhance performance during team meetings, handovers, appraisals, debriefing and feedback in which challenges and obstacles are reframed as opportunities and as strength-building experiences that are meaningful. The characteristics and strengtheners underpinning the meaningful facet are presented in Table 1.

Perceiving one's work as meaningful, or finding one's 'why', contributes to engagement, organisational commitment and satisfaction ${ }^{67}$. Workers are consistently exposed to the influence of how others appraise their work role, through the cues the convey ${ }^{68}$. Price, McGillis Hall ${ }^{69}$ identified 'making a difference' as a core sub-theme for nurses in making their career choice. As such, the work wellbeing job crafting and design innovations related to this facet include creating environmental spaces and creative opportunities to reinforce meaning, purpose, information sharing and strengthbased development.

\section{Connected}

Facet four, connected broadly encompasses having important connections with others. The connected facet's theoretical underpinnings include Attachment Theory ${ }^{70}$, Social Exchange Theory e.g., see ${ }^{71}$ and Self-Determination Theory ${ }^{23,53}$. Attachment Theory relates to the human tendency to seek and develop relationships with others ${ }^{70}$. Similar attachment dynamics have been identified in organisational relationships as sources of social support and membership ${ }^{72}$. For example, attachment dynamics are related to follower proactivity ${ }^{73}$ and creative problem solving ${ }^{74}$. Relatedness is a core element of needs satisfaction within Self-Determination Theory, facilitating autonomous motivation, wellbeing and enhanced performance ${ }^{53}$. Social Exchange Theory for a detailed review see ${ }^{71}$ suggests a 
series of interdependent social exchanges generate obligations which have the potential to generate high quality relationships in particular circumstances. This theory suggests different workplace exchange relationships benefit multiple stakeholders such as employees who benefit from the exchange of resources, knowledge, and support and thus engage in organisational citizenship-type behaviours ${ }^{75}$. Furthermore, satisfaction with coworker relationships positively correlates with both job and life satisfaction ${ }^{76}$.

The ICU nurses' proposed work wellbeing characteristics for the facet of connected ranged from professional communication, to relationships, and to teamwork. Examples of the nurses' identified strengtheners included a positive and team-oriented culture, peer support and mentoring, team building exercises and social activities. Integrating the ICU nurses' conceptions of work wellbeing characteristics and strengtheners with this theme suggests for ICU nurses, connected, could mean supporting and facilitating online social group connections, accessible team communication strategies. These might include the use of online and social media-based tools, and accessible and varied formal and informal regular and frequent social activities for engagement, networking and collaboration. Identifying creative opportunities to proactively engage colleagues in collaborative problem identification and problem-solving strategies could include the use of online forums, teams and competitions. The characteristics and strengtheners underpinning the connected facet are presented in Table 1.

Opportunities to enhance connections include social media for networking, organising, and bridging social capital ${ }^{77}$. Colleagues are also a key source of help and information, which reduces a 
peer's role ambiguity, conflict and overload and enhances organisational climate ${ }^{78}$. As such, the work wellbeing job crafting and design innovations related to this facet incorporate the three levels of 'me', 'we' and 'us' in the creation of spaces and opportunities for informal collaboration and socialisation during work breaks, personal expression and sharing ideas ('me' \& 'we'), and informal zones to enhance connection with personal and organisational values ('me', 'we' \& 'us').

\section{Innovative}

Facet five, innovative broadly encompasses innovation, flexibility, adaptability, creativity, motivation and curiosity. The innovative facet's theoretical underpinnings include Self-Determination Theory ${ }^{23,53}$, Strength Theory ${ }^{79}$ and Sen's ${ }^{80}$ Capability Approach. Self-Determination Theory relates to motivation, and suggests both performance and wellbeing are affected by motivation for job activities

${ }^{53}$. This motivation can be intrinsically or extrinsically controlled. Individuals are more likely to be intrinsically motivated when they have a sense of ownership, choice, autonomy (culture-dependent), have clear feedback and support ${ }^{53}$. Strength Theory builds on the Greek philosophers exploration of 'what is the good of a person', examining character and virtue ${ }^{61}$. Sen's Capability Approach considers the balance between freedoms and equality, centralising the importance of equalising human capability. Capability is considered the potential to achieve outcomes, described by Sen ${ }^{80}$ as "functionings" (p. 53), which have close links to subjective wellbeing ${ }^{81}$. This Capability Approach, as an evaluative framework for wellbeing, has been considered in the development of New Zealand policy. For example, the economic development strategy ${ }^{82}$ of the New Zealand Government's Treasury, and 
also the collaborative and integrated organisational quality improvement strategies for Auckland District Health Boards ${ }^{83}$.

The ICU nurses' proposed work wellbeing characteristics for the facet of innovative included support and workplace culture. Examples of the nurses' identified strengtheners included work variety and challenge, autonomy, professional development opportunities and safe fair workloads. Integrating the ICU nurses' conceptions of work wellbeing characteristics and strengtheners with this theme suggests for ICU nurses, innovative, could mean being proactive, embracing change, and focusing towards the future, the adoption of self-rostering and self-allocation, designing ICU's and systems to facilitate collegial support whether this is enhanced visibility or using technological innovations such as social media and online forums to improve change and communication. The characteristics and strengtheners of the innovative facet are presented in Table 1.

Key components of the innovative facet include innovation, creativity and curiosity. Creativity is correlated with subjective wellbeing ${ }^{84}$, and trait and daily curiosity support the development and persistence of wellbeing ${ }^{85,86}$. As such, the work wellbeing job crafting and design innovations related to this facet include the promotion of choice, control and space for curiosity, creativity and innovation, and environmental design for personalisation, support and transparency.

\section{DISCUSSION}

The five facets of ICU nurse work wellbeing (healthy, authentic, meaningful, connected, and innovative) identified in this research synthesis provided the foundation for a conceptual model of ICU 
nurse work wellbeing (Figure 1). The five facets highlighted work wellbeing might be best described as a collection of elements, as opposed to meeting an 'all-or-none' criteria. Future testing of this model may determine whether this finding is also true for these facets.

Insert Figure 1 here

The ICU nurse work wellbeing model is also illustrated in a variety of formats based on the 'me, we, us' framework in Figure 1. The three different formats (me, we, us) support the future use and testing of the model. For example, building and evaluating new ways of approaching appraisals, preceptoring and mentoring at the individual ('me') level; or team meetings, debriefings and educational activities at the team ('we') level; or at wider organisational, professional body and state level meetings at the 'us' level. Future exploration of this model might include participatory action research with groups of potential users of future interpretations of the conceptual model, to determine data and insights from the potentially synergistic interaction of participants.

Further exploration of the conceptual model may include 1) generating hypotheses regarding how it may be operationalised, 2) exploring measurement, and then 3) testing the magnitude and direction of relationships between facets thereby 4) enabling further theory development. The conceptual model illustrated in Figure 1 provides a basis for ICU nurses and their workplaces to begin, or continue, to explore their potential for the heliotropic opportunities for enhancing their working life, both independently and collaboratively. 
This research highlights the opportunity for all nurses to influence the workplace culture, including their reportedly most valued elements of work wellbeing, namely, respecting and feeling respected, valuing and feeling valued, and supporting and feeling supported. These drivers of work wellbeing transcend all levels, from the individual, to the, team, organisation, society and profession. Importantly, individual nurses have a great opportunity shape their workplace, drawing from strengthsbased approaches to afford new opportunities in how we think about, and work with others, whether this is in everyday or challenging situations, alone, with peers, managers or leaders.

\section{Strengths and limitations}

This secondary analysis has the strength of drawing together two related studies to develop new knowledge. However, there is the potential for existing researcher bias to be amplified through the secondary analysis and integration of findings from the original studies ${ }^{87,88}$. This was mitigated by: 1) the analysis being conducted by the same research team who collected and analysed the original data, 2) clear methods for the interpretation of data, 3) revisiting of raw data to ensure accuracy in interpretation, and 4) peer review from researchers with ICU nursing, non-ICU nursing, and psychology backgrounds.

Implications and recommendations for practice

The present research has contributed toward shifting the focus from illbeing toward intensive care nurse wellbeing. Intensive care nurse work wellbeing has been delineated, identifying the core facets of work wellbeing needed to inform future research. The ICU nurses' conceptions of work 
wellbeing and its strengtheners can now be incorporated in strategic and evidence-informed work wellbeing measures and programmes. One example is the recently proposed the New Zealand Treasury's Wellbeing Budget ${ }^{89}$ which provides a unique opportunity to use the conceptual model to engage in meaningful conversations with policy developers; asking important questions about each of the proposed facets and how this and future national and international budgets might be an enabler or barrier to ICU nurse work wellbeing. The proposed starting point is a systematic review to identify and appraise the existing measures of work wellbeing such as that described in the protocol of [blinded for peer review ${ }^{90}$ ]. For ICUs, opportunities for job crafting and redesign were identified and presented in a conceptual model of intensive care nurse work wellbeing. This model provides individual nurses, intensive care teams, healthcare organisations, and workers' wellbeing programme and policy developers practical opportunities to explore individual and collaborative ways to enhance intensive care nurse work wellbeing.

\section{CONCLUSIONS}

This research synthesis has illustrated the synergistic effect of a programme of research by drawing together two studies to highlight the five facets of ICU nurse work wellbeing: 1) healthy, 2) authentic, 3) meaningful, 4) connected and 5) innovative. Opportunities for job crafting and redesign were identified and presented in a conceptual model of ICU nurse work wellbeing. This model contributes new knowledge to now be explored and empirically investigated in terms of construct validity and theory development. Further, the model provides individual nurses, ICU teams, healthcare 
organisations, and workers' wellbeing programme and policy developers practical opportunities to explore individual and collaborative ways to enhance ICU nurse work wellbeing.

\section{What is already known}

1) Rather than there being a definition of ICU nurse work wellbeing with specific elements that meet an 'all-or-none' criteria, work wellbeing may be better described as a collection of elements, a rich and multifaceted construct, with some elements more central and important than others.

2) Intensive care nurses are cognisant of a wide range of both relational and organisational systems strengtheners.

\section{What this paper adds}

1) Opportunities for job crafting and redesign were identified and presented in a conceptual model of ICU nurse work wellbeing. This model has five facets: 1) healthy, 2) authentic, 3) meaningful, 4) connected and 5) innovative, and contributes new knowledge to now be explored and empirically investigated in terms of construct validity and theory development.

2) The model provides individual nurses, ICU teams, healthcare organisations, and workers' wellbeing programme and policy developers practical opportunities to explore individual and collaborative ways to enhance ICU nurse work wellbeing.

\section{REFERENCES}

This article is protected by copyright. All rights reserved. 
1. Epp K. Burnout in critical care nurses: A literature review. Dynamics: The Official Journal of the Canadian Association of Nurses. 2012;23:25-31.

2. Pereira S, Teixeira C, Carvalho A, Hernández-Marrero P. Compared to palliative care, working in intensive care more than doubles the chances of burnout: Results from a nationwide comparative study. PLoS One. 2016;11:e0162340.

3. Jenkins B, Warren N. Concept analysis: Compassion fatigue and effects upon critical care nurses. Crit Care Nurs Q. 2012;35:388-95.

4. Choe K, Kang Y, Park Y. Moral distress in critical care nurses: A phenomenological study. J Adv Nurs. 2015;71:1684-93.

5. Ganz F, Levy H, Khalaila R, Arad D, Bennaroch K, Kolpak O, et al. Bullying and its prevention among intensive care nurses. J Nurs Scholarsh. 2015;47:505-11.

6. Mäkikangas A, Kinnunen U, Feldt T, Schaufeli W. The longitudinal development of employee well-being: A systematic review. Work Stress. 2016;30:46-70.

7. World Health Organisation. WHO Global Plan of Action on Workers' Health (2008-2017): Baseline for Implementation. Geneva: WHO Document Production Services; 2013.

8. Proyer R, Gander F, Wellenzohn S, Ruch W. Strengths-based positive psychology interventions: A randomized placebo-controlled online trial on long-term effects for a signature strengths - vs. A lesser strengthsintervention. Front Psychol. 2015;6:1-14.

This article is protected by copyright. All rights reserved. 
9. Kern M, Waters L, Adler A, White M. Assessing employee wellbeing in schools using a multifaceted approach: associations with physical health, life satisfaction, and professional thriving. Psychology. 2014;5:500-13.

10. Seligman M. Flourish: A visionary new understanding of happiness and well-being. Sydney, Australia: William Heinemann; 2011.

11. Hone L, Jarden A, Schofield G, Duncan S. Measuring flourishing: The impact of operational definitions on the prevalence of high levels of wellbeing. International Journal of Wellbeing. 2014;4:62-90.

12. Vanhove A, Herian M, Perez A, Harms P, Lester P. Can resilience be developed at work? A meta-analytic review of resilience-building programme effectiveness. J Occup Organ Psychol. 2015;89:278-307.

13. Colman J. Optimal functioning: A positive psychology handbook. Booknook.biz: Jessica D. Coleman; 2010.

14. Maslow A. A dynamic theory of human motivation. In: Stacey C, DeMartino M, editors. Understanding human motivation. Cleveland, OH: Howard Allen Publishers; 1958. p. 26-47.

15. Csikszentmihalyi M. Beyond boredom and anxiety. San Francisco, CA: Jossey-Bass; 1975.

16. Bandura A. Self-efficacy: Toward a unifying theory of behavioral change. Psychol Rev. 1977;84:191-215.

17. Bandura A, Adams N. Analysis of self-efficacy theory of behavioral change. Cognit Ther Res. 1977;1:287-310.

18. Bronfenbrenner U. Developmental ecology through space and time: A future perspective. In: Moen P, Elder G, Luscher K, editors. Examining lives in context: Perspectives on the ecology of human development. Washington DC: American Psychological Association; 1995. 
19. Bronfenbrenner U. Lewinian space and ecological substance. Journal of Social Issues. 1977;33:199-212.

20. Carver CS, Scheier MF. Control theory: A useful conceptual framework for personality-social, clinical, and health psychology. Psychol Bull. 1982;92:111-35.

21. Bretherton I. Attachment theory: Retrospect and prospect. Monogr Soc Res Child Dev. 1985;50:3-35.

22. Bretherton I. The origins of attachment theory: John Bowlby and Mary Ainsworth. Dev Psychol. 1992;28:759-75.

23. Deci E, Ryan R. The "what" and "why" of goal pursuits: Human needs and the self-determination of behavior. Psychol Inq. 2000;11:227-68.

24. Forgeard M, Jayawickreme E, Kern M, Seligman M. Doing the right thing: Measuring wellbeing for public policy. International Journal of Wellbeing. 2011;1:79-106.

25. Dodge R, Daly A, Huyton J, Sanders L. The challenge of defining wellbeing. International Journal of Wellbeing. 2012;2:222-35.

26. Huppert F. Psychological well-being: Evidence regarding its causes and consequences. Applied Psychology: Health and Well-Being. 2009;1:137-64.

27. Patrick D, Guyatt G, Acquadro C. Patient-reported outcomes. In: Higgins J, Green S, editors. Cochrane handbook for systematic reviews of interventions 510 [updated March 2011]. http://handbook-51.cochrane.org/: The Cochrane Collaboration; 2011. 
28. World Health Organization. Constitution of the World Health Organization. Geneva: World Health Organization; 1946.

29. Ryff C. Happiness is everything, or is it? Explorations on the meaning of psychological well-being. J Pers Soc Psychol. 1989;57:1069-81.

30. Ryan R, Deci E. On happiness and human potentials: A review of research on hedonic and eudaimonic wellbeing. Annu Rev Psychol. 2001;52:141-66.

31. Huppert F, So T. Flourishing across Europe: Application of a new conceptual framework for defining wellbeing. Social Indicators Research. 2013;110:837-61.

32. Statistics New Zealand. Labour market statistics: September 2018 quarter. 2018.

33. Organization of Economic Cooperation and Development. Employment rate. 2018.

34. Munir F, McDermott H. Design of environments and work: Health, safety and well-being. In: Lewis R, Zibarras L, editors. Work and occupational psychology: Integrating theory and practice. London: Sage; 2013. p. 217-56.

35. Hackman J, Oldham G. Motivation through the design of work: Test of a theory. Organizational Behavior and Human Performance. 1976;16:250-79.

36. Verquer M, Beehr T, Wagner S. A meta-analysis of relations between person-organization fit and work attitudes. J Vocat Behav. 2003;63:473-89. 
37. Gordon H, Demerouti E, Bipp T, Le Blanc PM. The Job Demands and Resources Decision Making (JD-R-DM) Model. European Journal of Work and Organizational Psychology. 2015;24:44-58.

38. Wrzesniewski A, Dutton J. Crafting a job: Revisioning employees as active crafters of their work. The Academy of Management Review. 2001;26:179-201.

39. Demerouti E. Design your own job through job crafting. Eur Psychol. 2014;19:237-47.

40. Warr P. Differential activation of judgments in employee well-being. J Occup Organ Psychol. 2006;79:22544.

41. Jackson D, Hutchinson M, Peters K, Luck L, Saltman D. Understanding avoidant leadership in health care: findings from a secondary analysis of two qualitative studies. J Nurs Manag. 2013;21:572-80.

42. Ziebland S, Hunt K. Using secondary analysis of qualitative data of patient experiences of health care to inform health services research and policy. J Health Serv Res Policy. 2014;19:177-82.

43. Guest G, MacQueen K, Namey E. Applied thematic analysis. Thousand Oaks, California: SAGE Publications, Inc.; 2012.

44. Braun V, Clarke V. Using thematic analysis in psychology. Qualitative Research in Psychology. 2006;3:77-101.

45. Braun V, Clarke V. Successful qualitative research: A practical guide for beginners. London: Sage; 2013.

46. Paul C. A modified delphi approach to a new card sorting methodology. Journal of Usability Studies. 2008;4:7-30. 
47. Rugg G, McGeorge P. The sorting techniques: A tutorial paper on card sorts, picture sorts and item sorts. Expert Systems. 1997;14:80-93.

48. Macquarie. Macquarie Dictionary and Thesaurus Online. 7th ed. Australia: Pan Macmillan 2018.

49. (Blinded for peer review)

50. Caplan R. Person-environment fit theory and organizations: Commensurate dimensions, time perspectives, and mechanisms. J Vocat Behav. 1987;31:248-67.

51. Csikszentmihalyi M. Flow: The psychology of optimal experience. New York, NY: HarperCollins; 1990.

52. Oishi S, Diener E, Lucas R, Suh E. Cross-cultural variations in predictors of life satisfaction: Perspectives from needs and values. Personality and Social Psychology Bulletin. 1999;25:980-90.

53. Deci E, Olafsen A, Ryan R. Self-determination theory in work organizations: The state of a science. Annual Review of Organizational Psychology and Organizational Behavior. 2017;4:19-43.

54. Avolio B, Gardner W. Authentic leadership development: Getting to the root of positive forms of leadership. The leadership quarterly. 2005;16:315-38.

55. Ilies R, Wagner D, Wilson K, Ceja L, Johnson M, DeRue S, et al. Flow at work and basic psychological needs: Effects on well-being. Applied Psychology: An International Review. 2017;66:3-24.

56. Fullagar C, Kelloway E. 'Flow' at work: An experience sampling approach. J Occup Organ Psychol. 2009;82:595-615. 
57. van den Bosch R, Taris T. The authentic worker's well-being and performance: The relationship between authenticity at work, well-being, and work outcomes. The Journal of Psychology. 2014;148:659-81.

58. Ménard J, Brunet L. Authenticity and well-being in the workplace: A mediation model. Journal of Managerial Psychology. 2011;26:331-46.

59. Grandey A, Foo S, Groth M, Goodwin R. Free to be you and me: A climate of authenticity alleviates burnout from emotional labor. J Occup Health Psychol. 2012;17:1-14.

60. Heppner W, Kernis M, Nezlek J, Foster J, Lakey C, Goldman B. Within-person relationships among daily selfesteem, need satisfaction, and authenticity. Psychol Sci. 2008;19:1140-5.

61. Peterson C, Seligman M. Character strengths and virtues: A handbook and classification. New York: Oxford University Press; 2004.

62. Salancik G, Pfeffer J. A social information processing approach to job attitudes and task design. Adm Sci Q. 1978;23:224-53.

63. Steger M. Experiencing meaning in life: Optimal functioning at the nexus of well-being, psychopathology, and spirituality. In: Wong P, editor. The human quest for meaning. New York: Routledge; 2013. p. 21130.

64. Baumeister R, Vohs K, Aaker J, Garbinsky E. Some key differences between a happy life and a meaningful life. The Journal of Positive Psychology. 2013;8:505-16. 
65. Abe J. A longitudinal follow-up study of happiness and meaning-making. The Journal of Positive Psychology. 2016;11:489-98.

66. Cameron K, Dutton J, Quinn R. Positive organizational scholarship: Foundations of a new discipline. San Francisco, CA: Berrett-Koehler; 2003.

67. Geldenhuys M, Łaba K, Venter C. Meaningful work, work engagement and organisational commitment. SA Journal of Industrial Psychology. 2014;40:e1-e10.

68. Wrzesniewski A, McCauley C, Rozin P, Schwartz B. Jobs, careers, and callings: People's relations to their work. Journal of Research in Personality. 1997;31:21-33.

69. Price S, McGillis Hall L, Angus J, Peter E. Choosing nursing as a career: A narrative analysis of millennial nurses' career choice of virtue. Nurs Inq. 2013;20:305-16.

70. Bowlby J. Attachment and loss. London: Institute of Psycho-Analysis; 1969.

71. Cropanzano R, Mitchell M. Social exchange theory: An interdisciplinary review. Journal of management. 2005;31:874-900.

72. Hazan C, Shaver P. Love and work: An attachment-theoretical perspective. J Pers Soc Psychol. 1990;59:27080.

73. Wu C, Parker S. The role of leader support in facilitating proactive work behavior: A perspective from attachment theory. Journal of Management. 2017;43:1025-49. 
74. Mikulincer M, Shaver PR, Rom E. The effects of implicit and explicit security priming on creative problem solving. Cognition \& Emotion. 2011;25:519-31.

75. Li C, Hung C. The influence of transformational leadership on workplace relationships and job performance. Social Behavior \& Personality: An International Journal. 2009;37:1129-42.

76. Simon L, Judge T, Halvorsen-Ganepola M. In good company? A multi-study, multi-level investigation of the effects of coworker relationships on employee well-being. J Vocat Behav. 2010;76:534-46.

77. Huang L, Liu P. Ties that work: Investigating the relationships among coworker connections, work-related Facebook utility, online social capital, and employee outcomes. Comput Human Behav. 2017;72:512-24.

78. Chiaburu D, Harrison D. Do peers make the place? Conceptual synthesis and meta-analysis of coworker effects on perceptions, attitudes, OCBs, and performance. J Appl Psychol. 2008;93:1082-103.

79. Peterson C, Ruch W, Beermann U, Park N, Seligman M. Strengths of character, orientations to happiness, and life satisfaction. The Journal of Positive Psychology. 2007;2:149-56.

80. Sen A. Human rights and capabilities. Journal of Human Development. 2005;6:151-66.

81. Graham C, Nikolova M. Bentham or Aristotle in the development process? An empirical investigation of capabilities and subjective well-being. World Devel. 2015;68:163-79.

82. Treasury. Towards an inclusive economy. Wellington, NZ: The Treasury; 2001. 
83. Ministry of Health, Treasury, Health Quality and Safety Commission. Exploring the links between quality improvement strategies and organisational outcomes in four New Zealand District Health Boards. Wellington, NZ: Treasury; 2016.

84. Dolan P, Metcalfe R. The relationship between innovation and subjective wellbeing. Res Pol. 2012;41:148998.

85. Kashdan T, Steger M. Curiosity and pathways to well-being and meaning in life: Traits, states, and everyday behaviors. Motivation and Emotion. 2007;31:159-73.

86. Sheldon K, Jose P, Kashdan T, Jarden A. Personality, effective goal-striving, and enhanced well-being: Comparing 10 candidate personality strengths. Personality and Social Psychology Bulletin. 2015;41:57585.

87. Irwin S. Qualitative secondary data analysis: Ethics, epistemology and context. Progress in Development Studies. 2013;13:295-306.

88. Heaton J. Reworking qualitative data. London: Sage; 2004.

89. New Zealand Treasury. Wellbeing Budget. Wellington, New Zealand: New Zealand Treasury; 2019.

90. (Blinded for peer review) 


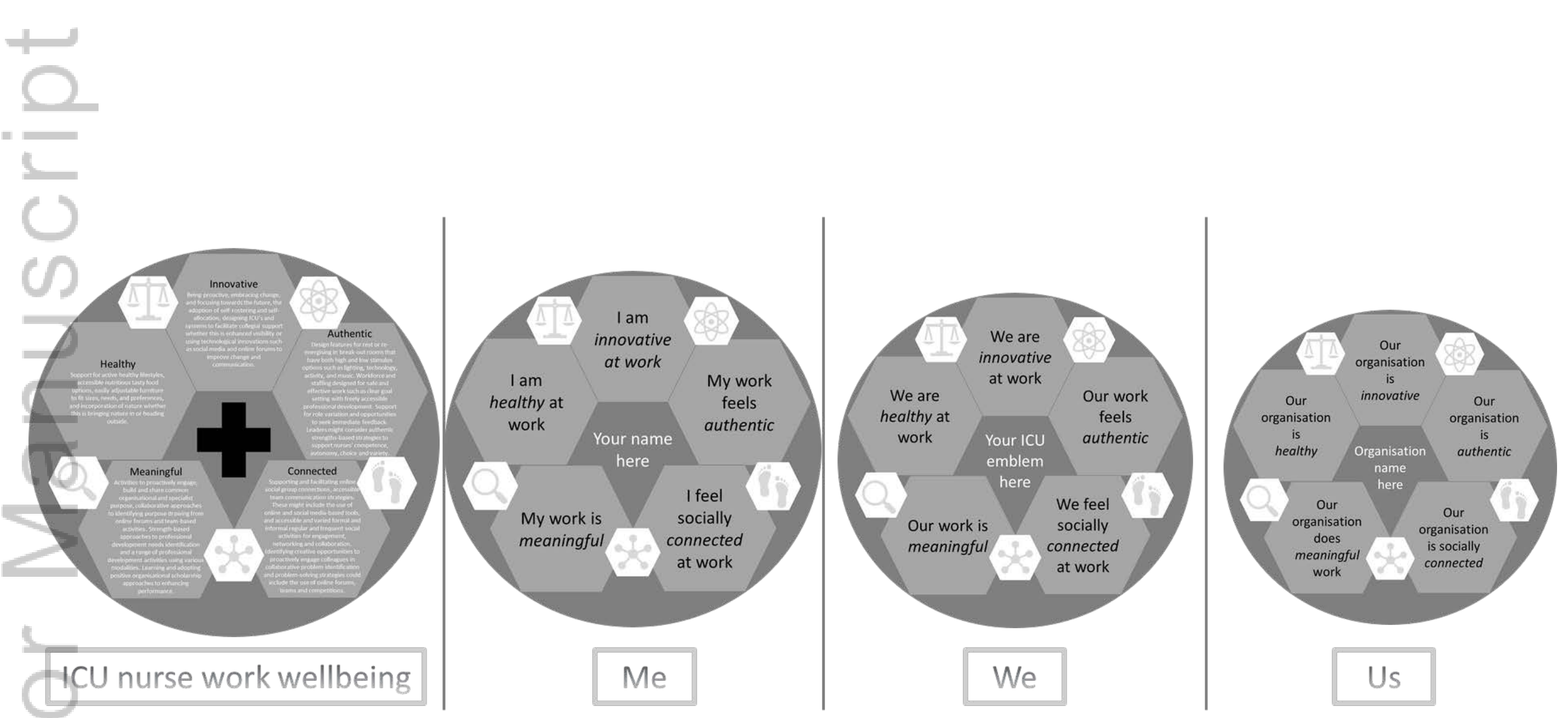

Figure 1. Conceptual model of five facets of ICU nurse work wellbeing with proposed 'me', 'we' and 'us' variations.

This article is protected by copyright. All rights reserved. 
Table 1. Facets of ICU nurse work wellbeing based on characteristics and strengtheners.

\begin{tabular}{|c|c|c|}
\hline Facets & $\begin{array}{l}\text { ICU nurse identified work wellbeing } \\
\text { characteristics }\end{array}$ & ICU nurse identified work wellbeing strengtheners \\
\hline Healthy & $\begin{array}{l}\text { Energy } \\
\text { Physical health } \\
\text { Work-life balance } \\
\text { Mental health } \\
\text { Rostering } \\
\text { Paid fairly } \\
\text { Income security } \\
\text { Resilience }\end{array}$ & 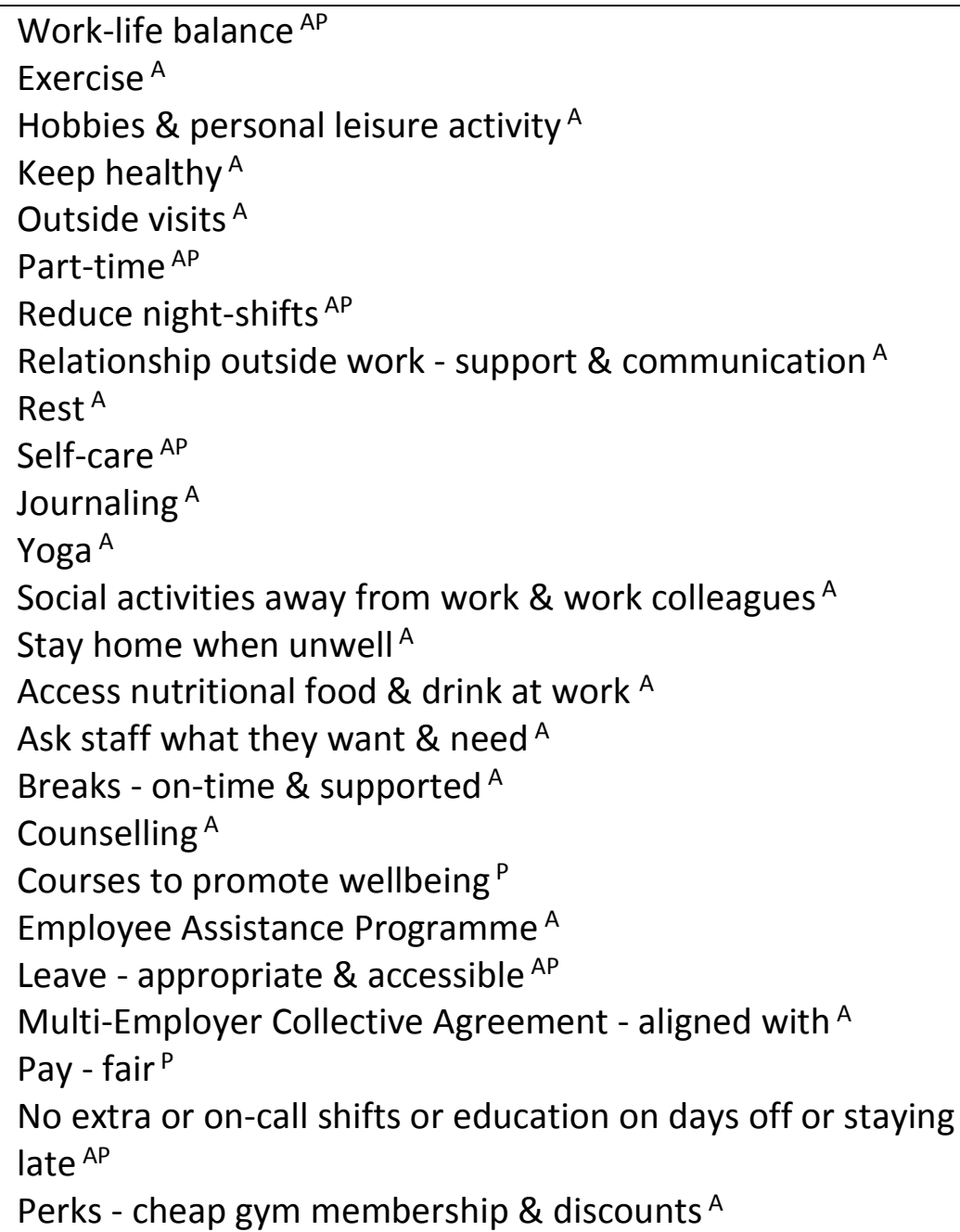 \\
\hline
\end{tabular}

This article is protected by copyright. All rights reserved. 


\begin{tabular}{|c|c|c|}
\hline Facets & $\begin{array}{l}\text { ICU nurse identified work wellbeing } \\
\text { characteristics }\end{array}$ & ICU nurse identified work wellbeing strengtheners \\
\hline & & $\begin{array}{l}\text { Rostering - self, safe, fair, flexible, good AP } \\
\text { Vaccinations - free } \& \text { accessible }\end{array}$ \\
\hline Authentic & $\begin{array}{l}\text { Energy } \\
\text { Humour } \\
\text { Work-life balance } \\
\text { Workplace culture }\end{array}$ & 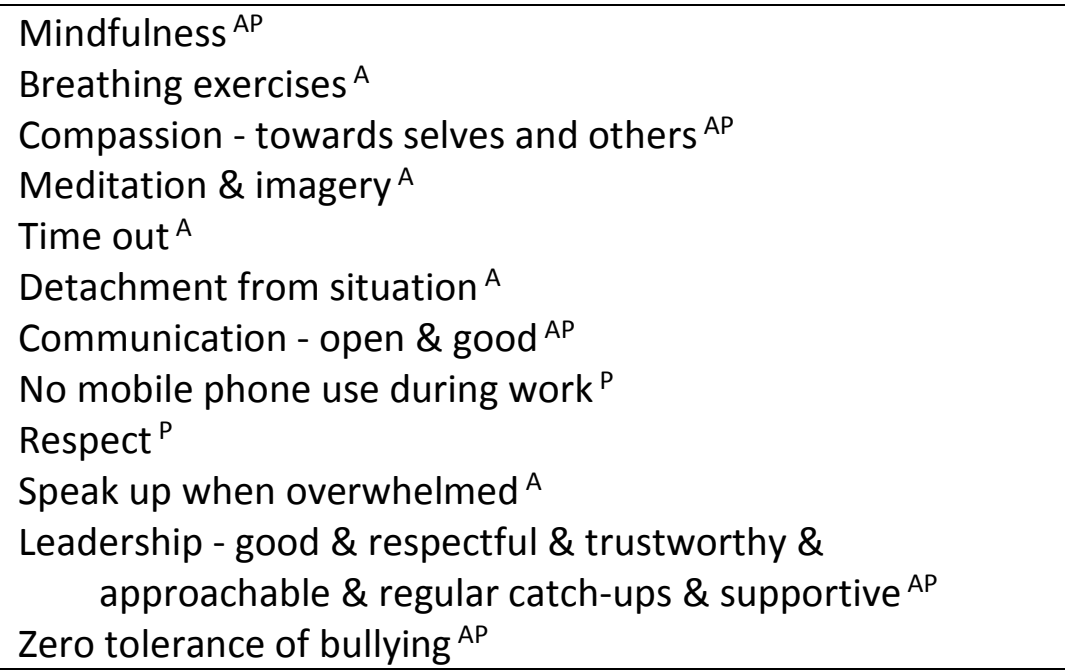 \\
\hline Meaningful & $\begin{array}{l}\text { Work safety } \\
\text { Caring } \\
\text { Appreciated } \\
\text { Workload } \\
\text { Leadership } \\
\text { Job satisfaction } \\
\text { Happiness } \\
\text { Nurse-patient relationships } \\
\text { Confidence in practice }\end{array}$ & $\begin{array}{l}\text { Feeling fulfilled }{ }^{P} \\
\text { Show appreciation AP } \\
\text { Teamwork }^{P} \\
\text { Annual appraisals }{ }^{A} \\
\text { Appreciation }{ }^{P} \\
\text { Debriefing - formal \& informal \& work-based \& non-work- } \\
\text { based AP } \\
\text { Environment - safe \& nice \& appropriate \& comfortable }{ }^{P} \\
\text { Feedback - regular, encouraging, positive, receptive to }{ }^{A P} \\
\text { Health and safety team - active }{ }^{A} \\
\text { Management - approachable \& supportive \& good with } \\
\quad \text { integrity \& fair \& encouraging \& resources well managed } \\
\text { AP }\end{array}$ \\
\hline
\end{tabular}

This article is protected by copyright. All rights reserved. 


\begin{tabular}{|c|c|c|}
\hline Facets & $\begin{array}{l}\text { ICU nurse identified work wellbeing } \\
\text { characteristics }\end{array}$ & ICU nurse identified work wellbeing strengtheners \\
\hline Connected & $\begin{array}{l}\text { Teamwork } \\
\text { Professional communication } \\
\text { Professional relationships }\end{array}$ & $\begin{array}{l}\text { Colleagues - nice \& friendly }{ }^{P} \\
\text { Culture - positive \& team \& open AP } \\
\text { Friendly \& welcoming to others }{ }^{A} \\
\text { Relationships - positive \& encouraging }{ }^{P} \\
\text { Social activities with colleagues and or social club AP } \\
\text { Mentoring AP } \\
\text { Peer support }{ }^{A P} \\
\text { Psychologist } \\
\text { Va } \\
\text { Valuing \& recognition of service AP } \\
\text { Supervision - access \& during work time }{ }^{A P} \\
\text { Team building exercises AP }\end{array}$ \\
\hline Innovative & $\begin{array}{l}\text { Support } \\
\text { Workplace culture }\end{array}$ & $\begin{array}{l}\text { Positive attitude }{ }^{A} \\
\text { Senior staff - approachable \& supportive }{ }^{A} \\
\text { Team communication AP } \\
\text { Work variety \& challenge }{ }^{P} \\
\text { Autonomy AP } \\
\text { Professional development - time \& opportunity \& supporting } \\
\text { AP } \\
\text { Safe staffing AP } \\
\text { Workload - safe \& fair \& achievable \& realistic }{ }^{\text {AP }}\end{array}$ \\
\hline
\end{tabular}

Note. This table reports re-analysed data including ICU nurse identified work wellbeing characteristics ${ }^{\text {(blinded for peer review) }}$ and strengtheners ${ }^{\text {(blinded }}$ for peer review); superscript ' $A$ ' denotes an actual strengthener, superscript ' $P$ ' denotes a potential strengthener. 


\section{University Library}

\section{- M M N E R VA A gateway to Melbourne's research publications}

Minerva Access is the Institutional Repository of The University of Melbourne

Author/s:

Jarden, RJ;Sandham, M;Siegert, RJ;Koziol-McLain, J

Title:

Conceptual model for intensive care nurse work well-being: A qualitative secondary analysis

Date:

2019-11-21

Citation:

Jarden, R. J., Sandham, M., Siegert, R. J. \& Koziol-McLain, J. (2019). Conceptual model for intensive care nurse work well-being: A qualitative secondary analysis. NURSING IN CRITICAL CARE, 25 (2), pp.74-83. https://doi.org/10.1111/nicc.12485.

Persistent Link:

http://hdl.handle.net/11343/286645 